\title{
Linear Free Energy and Reactivity-Selectivity Relationships in Reactions of Diarylcarbenium Ions with $\pi$-Nucleophiles
}

\author{
Herbert Mayr, ${ }^{*}$ Reinhard Schneider, and Ute Grabis
}

Contribution from the Institut für Chemie der Medizinischen Universität zu Lübeck, Ratzeburger Allee 160, D-2400 Lübeck 1, Federal Republic of Germany. Received October 25, 1989

\begin{abstract}
Second-order rate constants for the reactions of para-substituted diarylcarbenium ions $\left(\mathrm{X}-\mathrm{C}_{6} \mathrm{H}_{4}\right)\left(\mathrm{Y}-\mathrm{C}_{6} \mathrm{H}_{4}\right) \mathrm{CH}^{+}$ with various alkenes have been determined in $\mathrm{CH}_{2} \mathrm{Cl}_{2}$ solution at -70 to $-30^{\circ} \mathrm{C}$. Within each reaction series (constant alkene, variable $\mathrm{X}$ and $\mathrm{Y}$ ), the activation entropy remains constant, while the activation enthalpy increases with increasing electron releasing ability of $\mathrm{X}$ and $\mathrm{Y}$. Rate equilibrium relationships $\Delta G^{*}=-\alpha \Delta G_{1}^{\circ}+c\left(\Delta G_{1}^{\circ}=\right.$ ionization free energy for the equilibrium $\mathrm{Ar}_{2} \mathrm{CHCl}+\mathrm{BCl}_{3} \rightleftharpoons \mathrm{Ar}_{2} \mathrm{CH}^{+} \cdot \mathrm{BCl}_{4}^{-}$) give $\alpha$ values of 0.64-0.67 for terminal alkenes and 0.75-0.94 for nonterminal alkenes, indicating late transition states. All reaction series are connected by well-behaved linear reactivity-reactivity relationships. The relative reactivities of terminal alkenes are independent of $X$ and $Y$, i.e., selectivity is independent of reactivity (constant selectivity relationship). When nonterminal alkenes are included, linear selectivity-reactivity relationships are observed (as a consequence of the linear reactivity-reactivity relationships) which have positive, negative, or zero slopes, i.e., selectivity may increase, decrease, or remain constant, as the reactivity of the carbenium ions increases. In the reaction series with trimethylethylene and tetramethylethylene, isoparametric values have been directly measured: This is the rate constant in a reaction series, characteristic for the isokinetic substituent (here $\left.\left(p-\mathrm{CH}_{3}-\mathrm{C}_{6} \mathrm{H}_{4}\right)_{2} \mathrm{CH}^{+}\right)$at all temperatures and for all compounds of a reaction series (here $\left(\mathrm{X}-\mathrm{C}_{6} \mathrm{H}_{4}\right)\left(\mathrm{Y}-\mathrm{C}_{6} \mathrm{H}_{4}\right) \mathrm{CH}^{+}$) at the isokinetic temperature. The meaning of negative activation enthalpies in these reaction series is discussed. Correlation equations are given, which allow the prediction of rate constants for the reactions of diarylcarbenium ions with alkenes on the basis of $\mathrm{p} K_{\mathrm{R}^{+}}$values or ethanolysis rate constants of the corresponding alkyl chlorides.
\end{abstract}

The relationship between reactivity $(\log k)$ and selectivity ( $\log$ $k_{1} / k_{2}$ ) has intrigued chemists for many years. ${ }^{1}$ While it had been considered to be a fundamental law of chemistry that selectivity decreases with increasing reactivity, "the credibility of the reactivity-selectivity principle has undergone steady erosion over the past decade". " Ritchie's constant selectivity relationship (eq 1), ${ }^{\text {le }}$ which implies that the relative reactivity of pairs of nu-

$$
\log k_{\mathrm{N}} / k_{\mathrm{W}}=\mathrm{N}_{+}
$$

cleophiles toward carbenium ions and related compounds is always constant, independent of the nature of the cation, is probably the most prominent example for the violation of the reactivity-selectivity principle. Electrophile and nucleophile solvation has been employed to rationalize the physical basis of eq $1,{ }^{2}$ but the discussion on the origin of this relationship and its limitations is still going on. ${ }^{3}$

Alkenes represent a class of nucleophiles which have not been studied by Ritchie. Since differential solvation of alkenes and of diarylcarbenium ions can be excluded, ${ }^{4}$ reaction 2 appeared to be suited for providing novel information on scope and limitations of the Ritchie relationship. Therefore, we have employed the kinetic approach described in the preceding two articles ${ }^{4,5}$ to obtain rate constants for the reactions of a series of para-sub-

(1) (a) Stock, L. M.; Brown, H. C. Adv. Phys. Org. Chem. 1963, l, 35. (b) Huisgen, R. Angew. Chem. 1970, 82, 783; Angew. Chem., Int. Ed. Engl. 1970, 9,751. (c) Olah, G. A. Acc. Chem. Res. 1971, 4, 240. (d) Raber, D J.; Harris, J. M.; Hall, R. E.; Schleyer, P. v. R. J. Am. Chem. Soc. 1971, 93 , 4821. (e) Ritchie, C. D. Acc. Chem. Res. 1972, 5, 348. (f) Johnson, C. D. Chem. Rev. 1975, 75, 755. (g) Johnson, C. D. Tetrahedron 1980, 36, 3461. (h) Pross, A. Adv. Phys. Org. Chem. 1977, 14, 69. (i) Giese, B. Angew. Chem 1977, 89, 162; Angew. Chem. Int. Ed. Engl. 1977, 16, 125. (j) Giese, B. Acc. Chem. Res, 1984, 17, 438. (k) Ta-Shma, R.: Rappoport, Z. J. Am. Chem. Soc. 1983, 105, 6082. (1) Arnett, E. M.; Molter, K. J. Phys. Chem. 1986 90, 383. (m) Jencks, W. P. Chem. Rev. 1985, 85, 511. (n) Arnett, E. M.; Molter, K. E. Acc. Chem. Res. 1985, 18, 339. (o) Buncel, E.: Wilson, H. J. Chem. Educ. 1987, 64, 475. (p) Johnson, C. D.; Stratton, B. J. Chem. Soc., Perkin Trans. 2 1988, 1903. (q) Formosinho, S. J. J. Chem. Soc., Perkin Trans. 2 1988, 839. (r) Kane-Maguire, L. A. P.: Honig, E. D.; Sweigart, D. A. Chem. Rev. 1984, 84, 525. (s) Special Issue of lsr. J. Chem. 1985, 26. 303-428.

(2) (a) Pross, A. J. Am. Chem. Soc. 1976, 98, 776. (b) Ritchie, C. D. Pure Appl. Chem. 1979, 5l, 153. (c) Bertran, J; Anguiano, J. J. Mol. Struct. THEO CHEM 1985, 120,107

(3) Ritchie, C. D. Can. J. Chem. 1986, 64, 2239 and references cited therein

(4) Mayr, H.; Schneider, R.; Schade, C.; Bartl, J.; Bederke, R. J. Am. Chem. Soc., first of three papers in this issue.

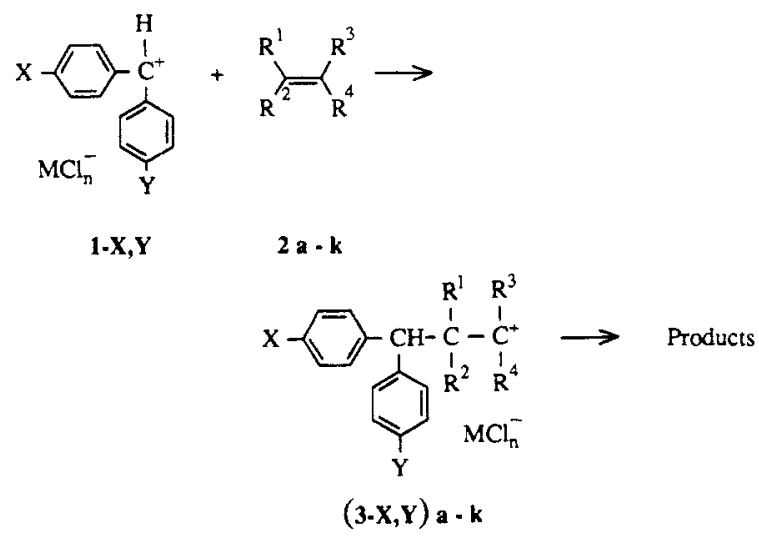

stituted diarylcarbenium ions $\mathbf{1 - X , Y}$ with some typical vinyl derivatives ( $2 a-k)$. This study was, furthermore, intended to provide information on whether the reactivity order of $\pi$-nucleophiles, which has been developed for the reference electrophile 1$\mathbf{O C H}_{3}, \mathbf{H},{ }^{5}$ also holds for other carbenium ions.

\section{Results}

The reactions of $1-\mathrm{X}, \mathrm{Y} \cdot \mathrm{MCl}_{n}{ }^{-}$with the nucleophiles 2 usually give the addition products $\mathbf{4} \mathbf{X}, \mathbf{Y}$ in quantitative yield, ${ }^{6}$ as described for the reactions of $\mathbf{1 - O C H}, \mathbf{H} \cdot \mathrm{BCl}_{4}^{-}$with these alkenes. ${ }^{5}$ While $2 \mathrm{~h}$ yields mixtures of the addition products $(\mathbf{4 - X}, \mathbf{Y}) \mathbf{h}$ and the corresponding indans $(\mathbf{5}-\mathbf{X}, \mathbf{Y}) \mathbf{h}$, the cyclized products 5 were formed almost exclusively from $1 \cdot \mathrm{X}, \mathrm{Y} \cdot \mathrm{BCl}_{4}{ }^{-}$and tetramethylethylene $\mathbf{2 k}$.

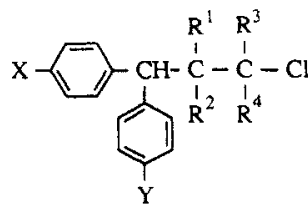

$(\mathbf{A}-\mathrm{X}, \mathbf{Y}) \mathrm{a} \cdot \mathrm{k}$

(5) Mayr, H.; Schneider, R.; Irrgang, B.; Schade, C. J. Am. Chem. Soc., preceding paper in this issue.

(6) For NMR spectroscopic data of the products, see: Schneider, R Dissertation, Universität Erlangen-Nürnberg, 1987. 
Scheme I

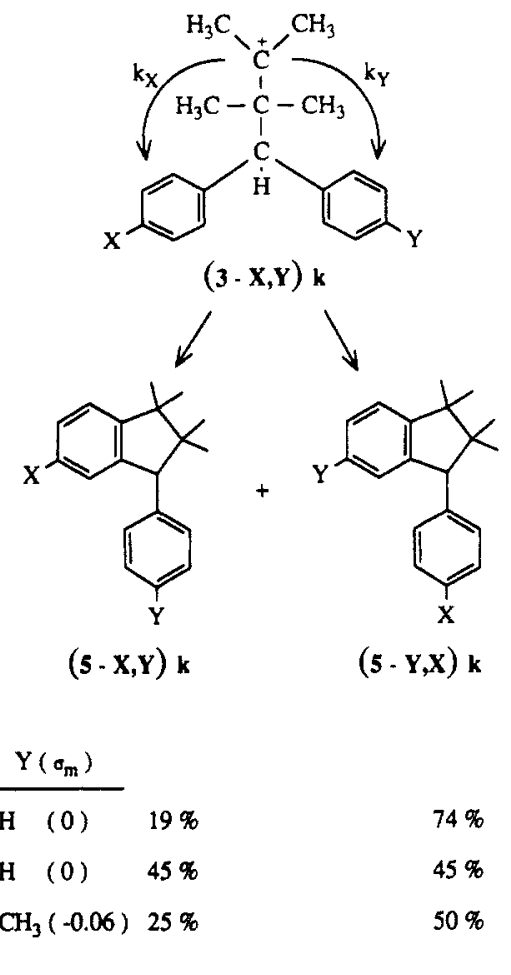

For $\mathrm{X} \neq \mathrm{Y}$, two modes of cyclization are possible, and the change of the product ratio $5-X, Y / 5-Y, X$ can roughly be rationalized on the basis of the $\sigma_{\mathrm{m}}$ values $^{7}$ as shown for the reactions of $1-X, Y$ with $2 \mathbf{k}$ in Scheme I. Allyltrimethylsilane (2e) undergoes an $\mathrm{S}_{\mathrm{E}} 2^{\prime}$ reaction with formation of 4,4-diaryl-1-butenes, ${ }^{8}$ and the rate-determining step of these reactions has also been shown to be the attack of $1-\mathrm{X}, \mathrm{Y}$ at the terminal vinyl position.?

The kinetic experiments were usually carried out with the $\mathrm{BCl}_{4}^{-}$ salts, employing the procedures described in the preceding articles. ${ }^{4,5}$ For syntheses of the less stabilized carbenium ions $\mathbf{1 - H}, \mathbf{H}$,

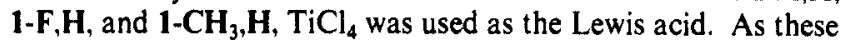
ions were combined with the alkenes $\mathbf{2 f}, \mathbf{g}$, the electrophilic attack yielded secondary carbenium ions, which were able to abstract $\mathrm{Cl}^{-}$from $\mathrm{TiCl}_{5}^{-}$, and the kinetic method described in ref 4 could be applied analogously. Compound $2 \mathbf{j}$ reacted similarly though reactions of $\mathrm{TiCl}_{5}^{-}$salts with more nucleophilic alkenes often initiated cationic polymerizations. For the determination of the activation parameters listed in Table I, rate constants have been measured at four different temperatures in the -70 to $-30^{\circ} \mathrm{C}$ range. Details are given in the Supplementary Material.

In accord with the results of the preceding articles, ${ }^{4,5} \Delta S^{*}$ varies with nucleophile structure, but is almost unaffected by variation of the substituents $X$ and $Y$ in the carbenium ions $1-X, Y$. Consequently, the large changes of reactivity associated with the replacements of $\mathrm{X}$ and $\mathrm{Y}$-in some cases five to six orders of magnitude - are almost entirely due to enthalpic effects.

\section{Linear Reactivity-Reactivity and Reactivity-Selectivity Relationships}

The effects of substituents directly conjugated to a carbenium center, which is generated or neutralized in the rate-determining step, can often be described by the Hammett equation (eq 3) using $\sigma^{+}$values. $^{7}$

$$
\log k / k_{H}=\sigma^{+} \rho
$$

(7) Exner, O. Correlation Analysis of Chemical Data; Plenum Press: New York, 1988; $\mathrm{p} \mathrm{I}$.

(8) Mayr, H.; Pock, R. Tetrahedron 1986, 42, 4211.

(9) Mayr, H.; Hagen, G. J. Chem. Soc., Chem. Commun. 1989, 91

(10) Nishida, S. J. Org. Chem. 1967, 32, 2697.
Figure 1 shows that the $\log k$ values $\left(=\log k_{0}\right)$ for the reactions of diarylcarbenium ions with 2-methyl-1-pentene (2r, reference reaction, eq 4$)^{4}$ give a moderately linear correlation with $\sum \sigma^{+}$ $(r=0.96)$, and comparable correlations with $\sum \sigma^{+}$are obtained for the other reaction series listed in Table I. Correlations of

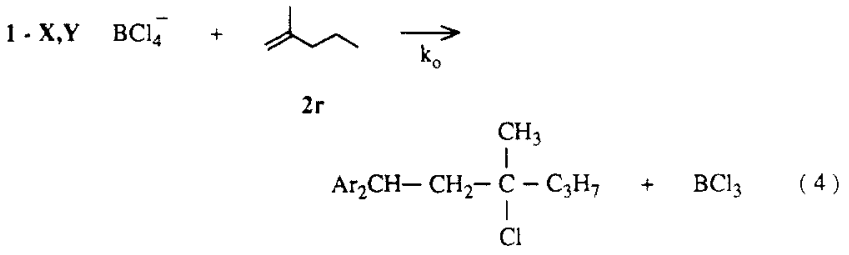

similarly low quality had been reported to link the solvolysis rate constants of diarylmethyl chlorides with $\sum \sigma^{+} .10$ For steric reasons, the two aryl rings of the ions $\mathbf{1 - X}, \mathbf{Y}$ cannot be coplanar, and the individual torsional angles depend on the relative donor abilities of both para substituents. Therefore, in reactions involving diarylcarbenium ions, a strict additivity of the $\sigma^{+}$values is not encountered.

Linear correlations of high quality were found, however, to connect the individual addition reactions with each other (Table II). Since 2-methyl-1-pentene ( $2 r$ ) has been combined with the greatest number of carbenium ions, this reaction (eq 4 ) was used as the reference reaction, and eq 5 allowed calculation of rate constants for the reaction of any carbenium ion $\mathbf{1 - X}, \mathbf{Y}$ with any of the alkenes $2 \mathbf{a}-\mathbf{k}$ from $k_{0}$ (reaction rate of $\mathbf{1 - X , Y}$ with 2methyl-1-pentene $(2 \mathrm{r})$ at $-70^{\circ} \mathrm{C}$ ) and the $s$ and $c$ values, which are given in Table II.

$$
\log k=s \log k_{0}+c
$$

Table II shows that the terminal vinyl derivatives are characterized by almost identical slopes $s$, which are close to 1 . The resulting parallel lines in Figure 2 imply that the relative reactivities of the terminal vinyl compounds are independent of the reactivity of the carbenium ions (Ritchie type behavior ${ }^{1 e}$ ). The ensuing "constant selectivity relationship" holds also for more reactive carbenium ions, as competition experiments with the in situ generated parent cation 1- $\mathrm{H}, \mathrm{H}$ (from $\mathrm{Ph}_{2} \mathrm{CHCl} / \mathrm{ZnCl}_{2}-\mathrm{OEt}_{2}$ in $\mathrm{CH}_{2} \mathrm{Cl}_{2},-78^{\circ} \mathrm{C}$ ) gave the same selectivities for terminal alkenes as determined for the better stabilized carbenium ions in this work (Figure 3). 11.8 It should be noted that the distances on the $y$ axis of Figure 3 correspond to Ritchie's $N_{+}$values. ${ }^{\text {le }}$

The reactivities of nonterminal alkenes are also linearily correlated with the rates of the reference reaction 4 , but now the slopes are greater than I (Table II). Figure 4 compares two nonterminal alkenes $(\mathbf{2 h}, \mathbf{j})$ with the terminal vinyl compounds $\mathbf{2 b}, \mathbf{2 c}$, and $2 \mathrm{e}$ to show that intersections of the reactivity graphs may be encountered. The bis ( $p$-anisyl)carbenium ion $\mathbf{1 - O C H}, \mathbf{O C H}_{3}$, for example, reacts 3.4 times faster with allyltrimethylsilane (2e) than with trimethylethylene $(2 \mathrm{~h})$, while the bis $(p$-tolyl)carbenium ion 1- $\mathbf{C H}_{3}, \mathbf{C H}_{3}$ attacks $\mathbf{2 h} 3.8$ times faster than 2 e, i.e., the reactivity order of these two nucleophiles depends on the nature of the carbenium ion $\mathbf{1 - X , Y}$

The linear combination of two linear functions yields another linear function. Therefore, the existence of linear reactivity-reactivity relationships $\left(\log k_{1} / \log k_{0}\right.$ and $\left.\log k_{2} / \log k_{0}\right)$, as shown in Figures 2 and 4 , necessitates the existence of linear selectivity-reactivity relationships $\left(\log \left(k_{1} / k_{2}\right) / \log k_{0}\right),{ }^{12}$ some of which are presented in Figure 5. In addition to the constant selectivity graphs (2e/2c, see also Figure 3), Figure 5 shows examples for the decrease of selectivity with increasing reactivity $(\mathbf{2 c} / \mathbf{2 j})$ and for the increase of selectivity with increasing reactivity $(\mathbf{2 c} / \mathbf{2 h}$; note that selectivity cannot be negative and is defined as the absolute value of $\log k_{1} / k_{2}$ ), i.e., all possible types of linear relationships between selectivity and reactivity are encountered in reactions of the carbenium ions $\mathbf{1 - X}, \mathbf{Y}$ with various pairs of $\pi$ nucleophiles.

(11) (a) Mayr, H.; Pock, R. Chem, Ber. 1986, 1/9, 2473. (b) Pock, R. Mayr, H. Chem. Ber. 1986, 119, 2497.

(12) Mayr, H.; Schneider, R.; Grabis, U. Angew. Chem. 1986, 98, 1034 Angew. Chem., Int. Ed. Eng!. 1986, 25, 1017. 
Table 1. Rate Constants $\left(-70^{\circ} \mathrm{C}\right)$ and Activation Parameters for the Reactions of Diarylcarbenium Salts with Alkenes $\left(\mathrm{CH}_{2} \mathrm{Cl}_{2}\right)$

\begin{tabular}{|c|c|c|c|c|c|}
\hline alkene & $1-X, Y$ & $\mathrm{MCl}_{n}^{-}$ & 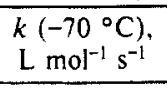 & $\begin{array}{c}\Delta H^{*} \\
\mathrm{~kJ} \mathrm{~mol}^{-1}\end{array}$ & $\frac{\Delta S^{*}}{\mathrm{~J} \mathrm{~mol}^{-1} \mathrm{~K}^{-1}}$ \\
\hline $2 a$ & $\begin{array}{l}\mathrm{CH}_{3}, \mathrm{CH}_{3} \\
\mathrm{OCH}_{3}, \mathrm{H} \\
\mathrm{OCH}_{3}, \mathrm{CH}_{3} \\
\mathrm{OCH}_{3}, \mathrm{OCH}_{3}\end{array}$ & $\begin{array}{l}\mathrm{BCl}_{4}^{-} \\
\mathrm{BCl}_{4}^{-} \\
\mathrm{BCl}_{4}^{-} \\
\mathrm{BCl}_{4}^{-}\end{array}$ & $\begin{array}{l}3.67 \times 10^{3} \\
2.33 \times 10^{1} \\
3.85 \\
3.13 \times 10^{-2}\end{array}$ & $\begin{array}{l}21.1 \pm 0.4 \\
23.0 \pm 0.4 \\
30.7 \pm 0.7\end{array}$ & $\begin{array}{l}-112 \pm 2^{a} \\
-117 \pm 2 \\
-119 \pm 3\end{array}$ \\
\hline $2 b$ & $\begin{array}{l}\mathrm{OPh}, \mathrm{H} \\
\mathrm{OCH}_{3}, \mathrm{H} \\
\mathrm{OCH}_{3}, \mathrm{CH}_{3} \\
\mathrm{OCH}_{3}, \mathrm{OCH}_{3}\end{array}$ & $\begin{array}{l}\mathrm{BCl}_{4}^{-} \\
\mathrm{BCl}_{4}^{-} \\
\mathrm{BCl}_{4}^{-} \\
\mathrm{BCl}_{4}^{-}\end{array}$ & $\begin{array}{l}2.61 \times 10^{4} \\
1.72 \times 10^{3} \\
3.04 \times 10^{2} \\
3.82\end{array}$ & $11.6 \pm 0.4$ & $-123 \pm 2$ \\
\hline $2 c$ & $\begin{array}{l}\mathrm{CH}_{3}, \mathrm{CH}_{3} \\
\mathrm{OPh}, \mathrm{H} \\
\mathrm{OCH}_{3}, \mathrm{H} \\
\mathrm{OPh} \mathrm{CH}_{3} \\
\mathrm{OCH}_{3}, \mathrm{CH}_{3} \\
\mathrm{OCH}_{3}, \mathrm{OPh} \\
\mathrm{OCH}_{3}, \mathrm{OCH}_{3}\end{array}$ & $\begin{array}{l}\mathrm{BCl}_{4}^{-} \\
\mathrm{BCl}_{4}^{-} \\
\mathrm{BCl}_{4}^{-} \\
\mathrm{BCl}_{4}^{-} \\
\mathrm{BCl}_{4}^{-} \\
\mathrm{BCl}_{4}^{-} \\
\mathrm{BCl}_{4}^{-}\end{array}$ & $\begin{array}{l}1.08 \times 10^{3} \\
1.09 \times 10^{2} \\
1.09 \times 10^{1} \\
9.4 \\
1.02 \\
7.53 \times 10^{-2} \\
1.22 \times 10^{-2}\end{array}$ & $\begin{array}{l}19.3 \pm 0.3 \\
25.2 \pm 0.3\end{array}$ & $\begin{array}{l}-127 \pm 1^{a} \\
-117 \pm 1\end{array}$ \\
\hline 20 & $\begin{array}{l}\mathrm{CH}_{3}, \mathrm{CH}_{3} \\
\mathrm{OPh}_{3} \mathrm{H} \\
\mathrm{OCH}_{3}, \mathrm{H} \\
\mathrm{OCH}_{3}, \mathrm{CH}_{3} \\
\mathrm{OCH}_{3}, \mathrm{OCH}_{3}\end{array}$ & $\begin{array}{l}\mathrm{BCl}_{4}^{-} \\
\mathrm{BCl}_{4}^{-} \\
\mathrm{BCl}_{4}^{-} \\
\mathrm{BCl}_{4}^{-} \\
\mathrm{BCl}_{4}^{-}\end{array}$ & $\begin{array}{l}2.04 \times 10^{3} \\
1.57 \times 10^{2} \\
1.56 \times 10^{1} \\
2.15 \\
2.21 \times 10^{-2}\end{array}$ & $\begin{array}{l}23.0 \pm 0.4 \\
33.4 \pm 0.4\end{array}$ & $\begin{array}{l}-106 \pm 2^{a} \\
-110 \pm 2\end{array}$ \\
\hline $2 \theta$ & $\begin{array}{l}\mathrm{CH}_{3}, \mathrm{CH}_{3} \\
\mathrm{OPh}, \mathrm{H} \\
\mathrm{OCH}_{3}, \mathrm{H} \\
\mathrm{OCH}_{3}, \mathrm{CH}_{3} \\
\mathrm{OCH}_{3}, \mathrm{OCH}_{3}\end{array}$ & $\begin{array}{l}\mathrm{BCl}_{4}^{-} \\
\mathrm{BCl}_{4}^{-} \\
\mathrm{BCl}_{4}^{-} \\
\mathrm{BCl}_{4}^{-} \\
\mathrm{BCl}_{4}^{-}\end{array}$ & $\begin{array}{l}1.77 \times 10^{4} \\
1.89 \times 10^{3} \\
1.87 \times 10^{2} \\
2.63 \times 10^{1} \\
2.81 \times 10^{-1}\end{array}$ & $\begin{array}{l}13.7 \pm 0.1 \\
15.5 \pm 0.4 \\
19.9 \pm 0.2 \\
26.1 \pm 0.1\end{array}$ & $\begin{array}{l}-111 \pm 0.3 \\
-122 \pm 2 \\
-117 \pm 1 \\
-124 \pm 0.4\end{array}$ \\
\hline $2 f$ & $\begin{array}{l}\mathrm{H}, \mathrm{H} \\
\mathrm{F}, \mathrm{H} \\
\mathrm{CH}_{3}, \mathrm{H} \\
\mathrm{CH}_{3}, \mathrm{CH}_{3}\end{array}$ & $\begin{array}{l}\mathrm{TiCl}_{5}^{-} \\
\mathrm{TiCl}_{5}^{-} \\
\mathrm{TiCl}_{5}{ }^{-} \\
\mathrm{TiCl}_{5}-\end{array}$ & $\begin{array}{l}2.14 \times 10^{2} \\
6.23 \times 10^{1} \\
4.57 \\
9.89 \times 10^{-2}\end{array}$ & $27.0 \pm 0.5$ & $-128 \pm 2$ \\
\hline$\sqrt{7}$ & $\begin{array}{l}\mathrm{CH}_{3}, \mathrm{H} \\
\mathrm{OCH}_{3}, \mathrm{H}\end{array}$ & $\begin{array}{l}\mathrm{TiCl}_{5}^{-} \\
\mathrm{BCl}_{4}^{-}\end{array}$ & $\begin{array}{l}7.37 \\
1.01 \times 10^{-3}\end{array}$ & $\begin{array}{l}16.9 \pm 0.2 \\
31.4 \pm 0.4\end{array}$ & $\begin{array}{l}-142 \pm 1 \\
-145 \pm 2^{a}\end{array}$ \\
\hline $2 h$ & $\begin{array}{l}\mathrm{CH}_{3}, \mathrm{CH}_{3} \\
\mathrm{OPh}_{3} \mathrm{H} \\
\mathrm{OCH}_{3}, \mathrm{H} \\
\mathrm{OCH}_{3}, \mathrm{CH}_{3} \\
\mathrm{OCH}_{3}, \mathrm{OPh} \\
\mathrm{OCH}_{3}, \mathrm{OCH}_{3}\end{array}$ & $\begin{array}{l}\mathrm{BCl}_{4}^{-} \\
\mathrm{BCl}_{4}^{-} \\
\mathrm{BCl}_{4}^{-} \\
\mathrm{BCl}_{4}^{-} \\
\mathrm{BCl}_{4}^{-} \\
\mathrm{BCl}_{4}^{-}\end{array}$ & $\begin{array}{l}6.79 \times 10^{4} \\
3.92 \times 10^{3} \\
2.47 \times 10^{2} \\
1.83 \times 10^{1} \\
7.5 \times 10^{-1} \\
8.38 \times 10^{-2}\end{array}$ & $\begin{array}{r}-1.4 \pm 0.6 \\
5.3 \pm 0.3 \\
7.5 \pm 0.1 \\
13.6 \pm 0.2 \\
21.9 \pm 0.7\end{array}$ & $\begin{array}{l}-156 \pm 3 \\
-147 \pm 1 \\
-159 \pm 0.3^{a} \\
-151 \pm 1 \\
-155 \pm 3\end{array}$ \\
\hline $2 i$ & $\begin{array}{l}\mathrm{CH}_{3}, \mathrm{CH}_{3} \\
\mathrm{OPh}_{3} \mathrm{H} \\
\mathrm{OCH}_{3}, \mathrm{H} \\
\mathrm{OCH}_{3}, \mathrm{CH}_{3} \\
\mathrm{OCH}_{3}, \mathrm{OCH}_{3}\end{array}$ & $\begin{array}{l}\mathrm{BCl}_{4}^{-} \\
\mathrm{BCl}_{4}^{-} \\
\mathrm{BCl}_{4}^{-} \\
\mathrm{BCl}_{4}^{-} \\
\mathrm{BCl}_{4}^{-}\end{array}$ & $\begin{array}{l}1.68 \times 10^{3} \\
1.38 \times 10^{2} \\
8.70 \\
8.59 \times 10^{-1} \\
4.6 \times 10^{-3}\end{array}$ & $17.7 \pm 0.2$ & $-136 \pm 1^{a}$ \\
\hline 2] & $\begin{array}{l}\mathrm{CH}_{3}, \mathrm{H} \\
\mathrm{CH}_{3}, \mathrm{CH} \mathrm{H}_{3} \\
\mathrm{OPh}, \mathrm{H} \\
\mathrm{OCH}_{3}, \mathrm{H} \\
\mathrm{OCH}_{3}, \mathrm{CH}_{3}\end{array}$ & $\begin{array}{l}\mathrm{TiCl}_{5}^{-} \\
\mathrm{BCl}_{4}^{-} \\
\mathrm{BCl}_{4}^{-} \\
\mathrm{BCl}_{4}^{-} \\
\mathrm{BCl}_{4}^{-}\end{array}$ & $\begin{array}{l}2.4 \times 10^{4} \\
9.97 \times 10^{2} \\
1.01 \times 10^{2} \\
3.87 \\
1.88 \times 10^{-1}\end{array}$ & $15.5 \pm 0.4$ & $-154 \pm 2^{a}$ \\
\hline$y=($ & $\begin{array}{l}\mathrm{CH}_{3}, \mathrm{CH}_{3} \\
\mathrm{OPh} \mathrm{H} \\
\mathrm{OCH}_{3}, \mathrm{H} \\
\mathrm{OCH}_{3}, \mathrm{CH}_{3} \\
\mathrm{OCH}_{3}, \mathrm{OPh} \\
\mathrm{OCH}_{3}, \mathrm{OCH}_{3}\end{array}$ & $\begin{array}{l}\mathrm{BCl}_{4}^{-} \\
\mathrm{BCl}_{4}^{-} \\
\mathrm{BCl}_{4}^{-} \\
\mathrm{BCl}_{4}^{-} \\
\mathrm{BCl}_{4}^{-} \\
\mathrm{BCl}_{4}^{-}\end{array}$ & $\begin{array}{l}3.68 \times 10^{3} \\
1.96 \times 10^{2} \\
5.62 \\
3.39 \times 10^{-1} \\
4.02 \times 10^{-3} \\
4.14 \times 10^{-4}\end{array}$ & $\begin{array}{r}-0.8 \pm 0.2 \\
8.0 \pm 0.2 \\
13.6 \pm 0.2 \\
22.9 \pm 0.2 \\
\end{array}$ & $\begin{array}{l}-177 \pm 1 \\
-188 \pm 1^{\circ} \\
-184 \pm 1 \\
-194 \pm 1\end{array}$ \\
\hline
\end{tabular}

${ }^{a}$ Reference 5 . ${ }^{b}$ These data refer to the gross reaction. For this alkene they are not identical with the rate of attack of $1-X, Y$ at $2 k .{ }^{16}$

Interesting behavior is exhibited by the couple $\mathbf{2 e} / \mathbf{2 h}$. Starting at the left edge of Figure 5 , the selectivity decreases with increasing reactivity, goes through 0 , and increases again with opposite relative reactivity. Certain substituents at the diarylcarbenium ions (electron releasing ability between that of $\mathrm{OCH}_{3}, \mathrm{CH}_{3}$ and $\mathrm{OCH}_{3}, \mathrm{H}$ for the pair $\mathbf{2 e} / \mathbf{2 h}$ ) give rise to zero selectivity and are therefore called aselective substituents (by analogy with the isokinetic substituent; see below). Figure 5 shows that for any couple of nucleophiles with different values of $s$ (Table II) an aselective substituent can be found, which is characteristic for a certain temperature. The carbenium ion with the aselective substituent can be identified by its reactivity toward $2 \mathbf{r}\left(\log k_{0}\right)$, and is obtained from eq 5 , by using the $s$ and $c$ values given in Table II.

$$
\text { aselective substituent: } \quad \log k_{0}=-\frac{c_{1}-c_{2}}{s_{1}-s_{2}}
$$

The aselective substituent of ten falls outside the range of this experimental investigation, but the couple $\mathbf{2 c} / \mathbf{2} \mathbf{j}$ is another case, for which an aselective substituent has directly been observed. As derived from the directly measured rate constants (Figure 5), in situ generated bis $\left(p\right.$-tolyl)carbenium ions $\left(\mathbf{1}-\mathbf{C H}_{3}, \mathbf{C H}_{3}\right)$ have previously been reported to show practically no selectivity between trans- $\beta$-methylstyrene and styrene $\left(k_{2 \mathrm{ij}} / k_{2 \mathrm{c}}=1.16\right)$ in competition experiments. ${ }^{11 \mathrm{~b}}$ Extrapolation of the $\mathbf{2 j} / \mathbf{2 c}$ correlation line to the right (Figure 5) now explains, why an analogous competition experiment with the parent benzhydryl cation $\mathbf{1 - H}, \mathbf{H}$ showed a considerable preference for the methyl-substituted styrene $\left(k_{2 \mathrm{j}} / k_{2 \mathrm{c}}\right.$ 


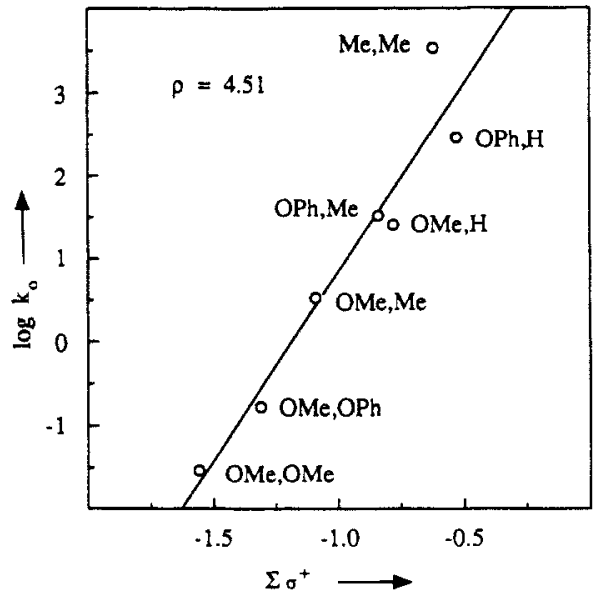

Figure 1. Correlation of the rate constants of the reactions of diarylcarbenium tetrachloroborates $\left(1-\mathrm{X}, \mathrm{Y} \cdot \mathrm{BCl}_{4}{ }^{-}\right)$with 2-methyl-1-pentene (2r) $\left(-70^{\circ} \mathrm{C}, \mathrm{CH}_{2} \mathrm{Cl}_{2}\right)$ with $\sum \sigma^{+} ; \rho=4.51$.

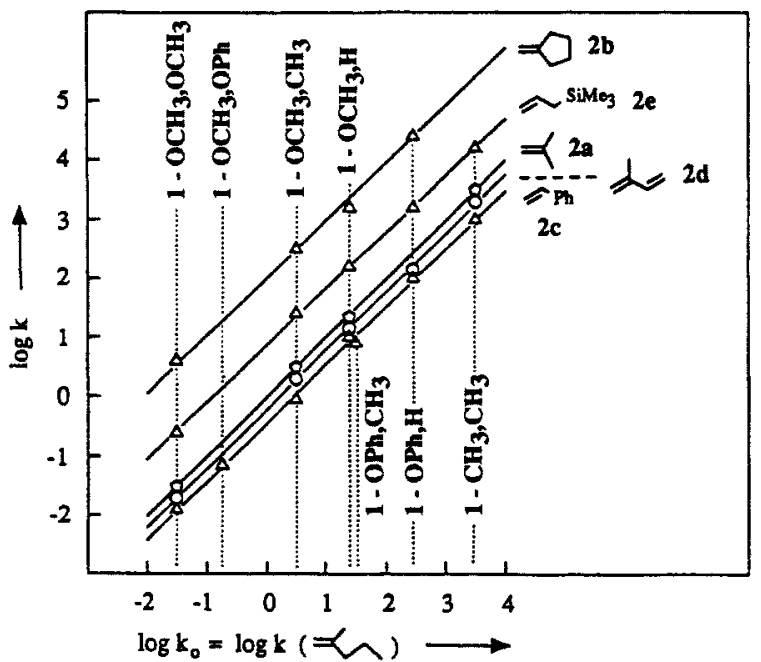

Figure 2. Correlation of the reactivities $(\log k)$ of terminal vinyl derivatives toward diarylcarbenium ions $\mathbf{1 \cdot X}, \mathbf{Y}$ with the corresponding reactivities $\left(\log k_{0}\right)$ of 2-methyl-1-pentene $\left(-70^{\circ} \mathrm{C}, \mathrm{CH}_{2} \mathrm{Cl}_{2}\right)$.

$=4.37),{ }^{116}$ behavior which was puzzling when only relative reactivities were available. ${ }^{11}$

What is the physical meaning of the slopes $s$ (eq 5 and Table II), which give rise to the reactivity selectivity pattern discussed above? During the attack of the carbenium ions 1-X,Y at the $\pi$-system of the nucleophiles, positive charge is transferred from the benzhydryl fragment to the $\alpha$-carbon of the alkene. The greater $s$, the further the transfer of charge must have proceeded in the transition state, for which a structure like 6 is assumed.

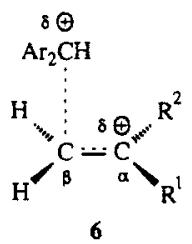

More quantitative information about the amount of charge transfer in the transition state can be obtained by comparing $\Delta G^{*}$ of these reaction series with the free energy of ionization for the corresponding benzhydryl chlorides (eq 7, Figure 6) with $\Delta G_{1}^{\circ}$ referring to the equilibrium $\mathrm{Ar}_{2} \mathrm{CHCl}+\mathrm{BCl}_{3}=1-\mathrm{X}, \mathrm{Y} \cdot \mathrm{BCl}_{4}{ }^{-13}$

$$
\Delta G^{*}=-\alpha \Delta G_{1}^{\circ}+\text { constant }
$$

Figure 6 shows that the $\alpha$ values for the terminal alkenes $2 r$ and $2 \mathrm{f}$ are 0.67 and 0.63 , respectively, and since $\alpha=0.67 \mathrm{~s}$

(13) (a) Schade, C.; Mayr, H.; Arnett, E. M. J. Am. Chem. Soc. 1988, 110, 567. (b) Schade, C.; Mayr, H. Tetrahedron 1988, 44, 5761.
Table II. Correlations between the Reactivities of Diarylcarbenium Ions 1-X,Y toward Various Vinyl Derivatives $\left(-70^{\circ} \mathrm{C}, \mathrm{CH}_{2} \mathrm{Cl}_{2}\right)^{a}$

\begin{tabular}{clll}
\hline alkene & \multicolumn{1}{c}{$s$} & \multicolumn{1}{c}{$c$} & \multicolumn{1}{c}{$r$ (no. of points) } \\
\hline $\mathbf{2 r}$ & 1.00 & 0.000 & reference reaction \\
$\mathbf{2 a}$ & $1.000 \pm 0.015$ & $0.014 \pm 0.030$ & $0.9998(4)$ \\
$\mathbf{2 b}$ & $0.948 \pm 0.034$ & $2.00 \pm 0.06$ & $0.9987(4)$ \\
$\mathbf{2 c}$ & $0.978 \pm 0.017$ & $-0.418 \pm 0.033$ & $0.9992(7)$ \\
$\mathbf{2 d}$ & $0.977 \pm 0.008$ & $-0.174 \pm 0.016$ & $0.99991(5)$ \\
$\mathbf{2 e}$ & $0.950 \pm 0.006$ & $0.918 \pm 0.012$ & $0.99995(5)$ \\
$\mathbf{2 h}$ & $1.164 \pm 0.011$ & $0.722 \pm 0.022$ & $0.9998(6)$ \\
$\mathbf{2 i}$ & $1.106 \pm 0.011$ & $-0.633 \pm 0.025$ & $0.9998(5)$ \\
$\mathbf{2} \mathbf{j}$ & $1.248 \pm 0.091$ & $-1.26 \pm 0.21$ & $0.995(4)$ \\
$\mathbf{2 k}$ & $1.394 \pm 0.021$ & $-1.25 \pm 0.04$ & $0.9995(6)$ \\
\hline
\end{tabular}

${ }^{\circ}$ Correlations according to eq $5 ; \log k_{0}=3.531\left(1-\mathbf{C H}_{3}, \mathbf{C H}_{3}\right), 2.456$ $(1-\mathbf{O P h}, \mathbf{H}), 1.519\left(1-\mathbf{O P h}, \mathbf{C H}_{3}\right), 1.412\left(1-\mathbf{O C H}_{3}, \mathrm{H}\right), 0.529(\mathbf{1 - O C H}$ $\left.\mathbf{C H}_{3}\right),-0.772(\mathbf{1 - O C H}, \mathbf{O P h}),-1.535\left(\mathbf{1}-\mathbf{O} \mathbf{C H}_{3}, \mathbf{O C H}\right)$; reference 4 .

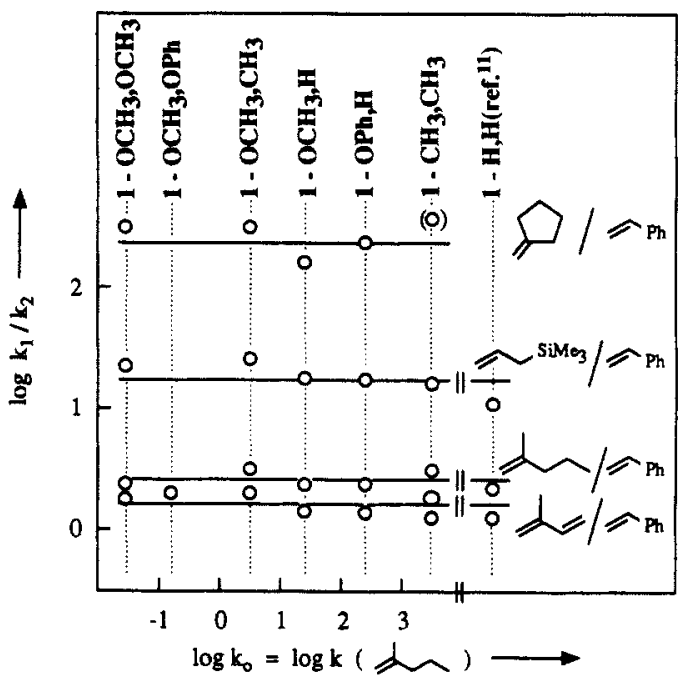

Figure 3. Constant selectivity relationship: the relative reactivity of two terminal vinyl derivatives $\left(\log k_{1} / k_{2}\right)$ toward $1-X, Y$ is independent of the reactivity $\left(\log k_{0}\right)$ of the diarylcarbenium ion $\mathbf{1 - X}, \mathbf{Y}$.

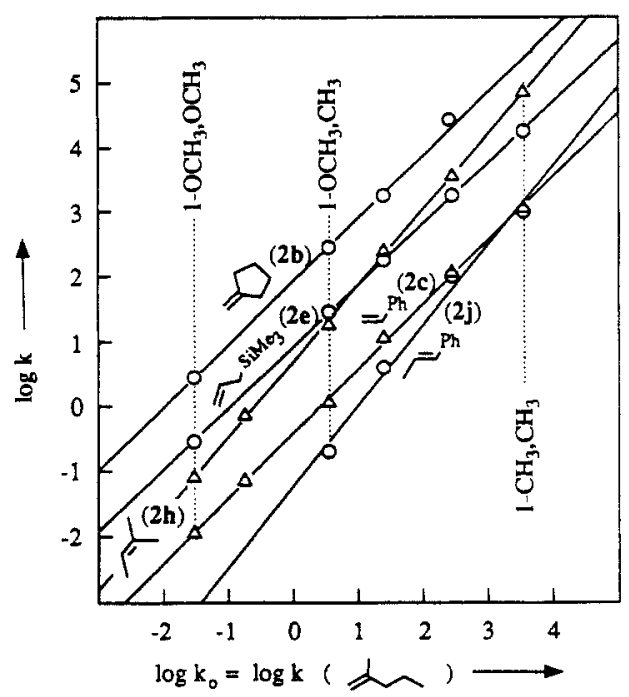

Figure 4. Correlation of the reacvities $(\log k)$ of various types of vinyl compounds 2 toward diarylcarbenium ions (1-X,Y) with the corresponding reactivities $\left(\log k_{0}\right)$ of 2 -methyl-1-pentene $(2 \mathrm{r})\left(-70^{\circ} \mathrm{C}\right.$, $\mathrm{CH}_{2} \mathrm{Cl}_{2}$ ).

(combination of eqs 5 and 7, $s$ from Table II), the $\alpha$ values for all other terminal vinyl compounds also are of similar magnitude. The rate equilibrium relationship (7) implies that in the transition states of the reactions with terminal alkenes approximately two-thirds of the positive charge has been removed from the diarylmethyl fragment. ${ }^{14}$ On the other hand, we have derived

(14) Thea, S.; Williams, A. Chem. Soc. Rev. 1986, 15, 125. 


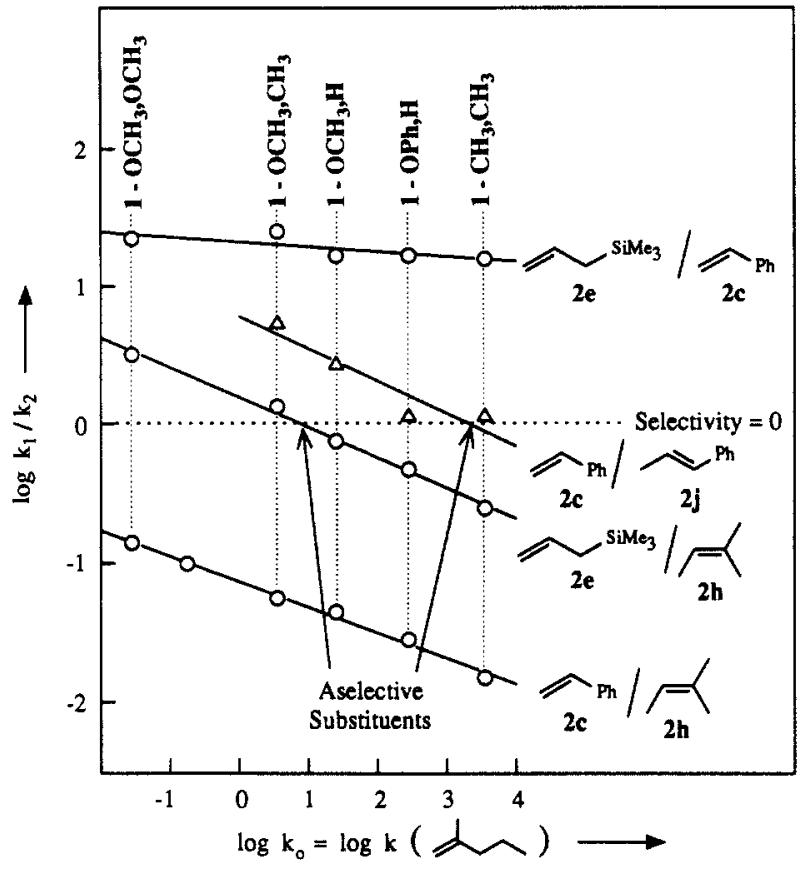

Figure 5. Linear selectivity-reactivity relationships as a consequence of linear reactivity-reactivity relationships: selectivity ( $\equiv\left|\log k_{1} / k_{2}\right|$ ) may decrease $(\mathbf{2 c} / \mathbf{2 j})$, increase $(\mathbf{2 c} / \mathbf{2 h})$ or remain constant $(\mathbf{2 e} / \mathbf{2 c})$ as the reactivity $\left(\log k_{0}\right)$ of the diarylcarbenium ions $(1-X, Y)$ increases $\left(-70^{\circ} \mathrm{C}\right.$, $\mathrm{CH}_{2} \mathrm{Cl}_{2}$ )

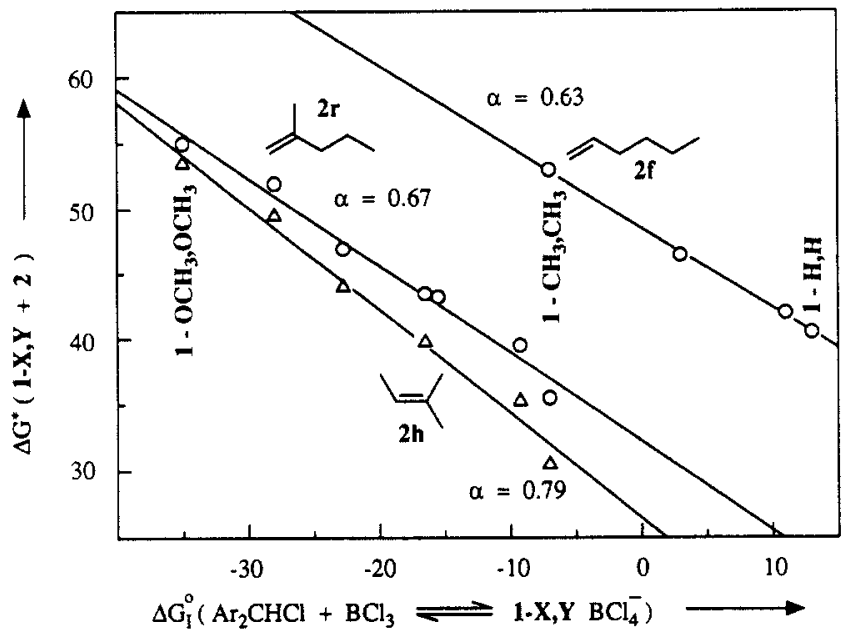

Figure 6. Correlations between the activation free energies for the reactions of diarylcarbenium ions $1-X, Y$ with some alkenes $\left(\mathrm{CH}_{2} \mathrm{Cl}_{2},-70\right.$ $\left.{ }^{\circ} \mathrm{C}\right)$ and the ionization free energies $\left(\mathrm{BCl}_{3}, \mathrm{CH}_{2} \mathrm{Cl}_{2},-70^{\circ} \mathrm{C}\right)$ of the corresponding diarylmethyl chlorides $\left(\mathrm{kJ} \mathrm{mol}^{-1}\right)$.

from the relative reactivities of alkenes that about one-half of a positive charge unit has arrived at the $\alpha$-carbon in the transition state. ${ }^{5}$ Partial bridging, which locates some charge at the $\beta$-carbon of 6 may account for this difference. ${ }^{15}$

Charge transfer is further advanced in reactions with the alkenes $2 \mathrm{~h}-\mathbf{j}(\alpha=0.75-0.84)$, which carry one alkyl group at the initially attacked vinylic position. The $\alpha$ value of 0.94 for the reaction of $1-X, Y$ with $2 k$ indicates that charge transfer from the diarylmethyl fragment to tetramethylethylene must be almost complete in the transition state. In this reaction series, the formation of the cation $(3-X, Y) k$ has been found to be reversible, and the cyclization step is rate-determining. ${ }^{16}$ Since the rate of the cyclization reaction is only slightly affected by the nature of $\mathrm{X}$ and $\mathrm{Y}$ (see product distribution in Scheme $\mathrm{I}$ ), one observes an

(15) Nonperfect synchronization represents an alternative explanation: Bernasconi, C. F. Acc. Chem. Res. 1987, 20,301.

(16) Schneider, R.; Mayr, H. Unpublished results.

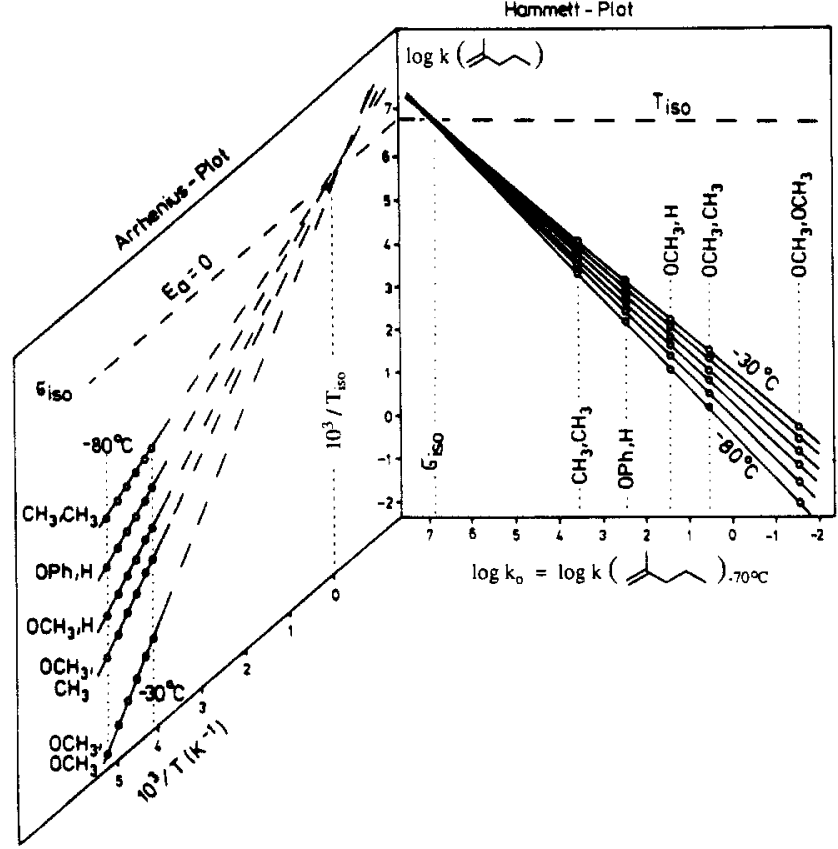

Figure 7. Rate constants $(\log k)$ for the reactions of diarylcarbenium ions 1-X,Y toward 2-methyl-1-pentene (2r) as a function of reciprocal temperature (left) and of substituents (right).

$\alpha$ value close to 1, i.e., in the transition state no charge resides at the positions substituted by $X$ and $Y$.

The linearity of the reactivity-reactivity relationships over a wide range and the constant value of $\alpha$ for all terminal vinyl derivatives indicates, that the transition-state structure is similar in all these reactions. Structural variations $\delta R$ in the alkenes $\mathrm{H}_{2} \mathrm{C}=\mathrm{CR}^{1} \mathrm{R}^{2}$ influence the reactivity toward all carbenium ions 1-X,Y by the same amount $\delta \Delta G^{*}$. Analogously, structural variations $\delta \mathrm{X}$ and $\delta \mathrm{Y}$ in the carbenium ions $\mathbf{1 - X}, \mathrm{Y}$ influence the reactivity toward all terminal alkenes by the same amount $\delta \Delta G^{*}$. It has to be concluded, therefore, that the transition-state structure remains unaffected if structural modifications are carried out at positions remote from the reaction centers. On the other hand, if the structural changes take place at the attacked vinylic position, i.e., at one of the reaction centers, a variation of $\alpha$ is observed, indicating that the transition-state structure has been affected. The later transition state in reactions of nonterminal alkenes, which is derived from the greater value of $\alpha$, is also characterized by a more negative value of the activation entropy.

Temperature Effects: Isokinetic Relationships and Aselective Temperatures. It has been emphasized that the existence of an isokinetic relationship, i.e. the proportional variation of $\Delta H^{*}$ and $\Delta S^{*}$ in a reaction series (eq 8 ), is a necessary condition for the existence of linear free energy relationships at different temperatures. ${ }^{17}$

$$
\delta \Delta H^{*}=\beta \delta \Delta S^{*}
$$

At the isokinetic temperature $T_{\text {iso }}=\beta$, structural changes do not affect the rate constant of a reaction series since the changes of $\Delta H^{*}$ are counterbalanced by changes of $\Delta S^{*}$. As the variation of $\mathrm{X}$ and $\mathrm{Y}$ hardly affects $\Delta S^{*}$ of reaction (2) (Table I), we are dealing with special cases of eq 8 , so-called isoentropic series, for which $T_{\text {iso }}$ must be infinite. This behavior is demonstrated for the reference reaction (eq 4 ) in the Arrhenius plot depicted on the left side of Figure 7 . The reactivity differences of the various carbenium ions $\mathbf{1 - X , Y}$ decrease with increasing temperature, and at $T_{\text {iso }}=\infty$, all carbenium ions react with the same rate $(\log k$ $\approx 6.8$ ), i.e., reactivity has become independent of structure. The same set of data can be presented in a Hammett plot (Figure 7,

(17) Leffler, J. E.; Grunwald, E. Rates and Equilibria of Organic Reactions; Wiley: New York, 1963; p 155; one referee pointed out, however, that in ionic reactions $\Delta H^{*}$ may not be temperature independent, an assumption made for the following discussion. 
Table III. Isokinetic Substituents (characterized by $\left.\mathrm{p}_{\mathrm{R}^{+}}\right)^{20}$ and Isoparametric Values for the Reactions of Diarylcarbenium Ions with the Vinyl Derivatives $2 \mathrm{a}-\mathrm{k}$ and $2 \mathrm{r}$ in $\mathrm{CH}_{2} \mathrm{Cl}_{2}{ }^{a, b}$

\begin{tabular}{|c|c|c|c|c|c|}
\hline alkene & $\begin{array}{l}\log A= \\
\log k_{\text {iso }}\end{array}$ & $\mathrm{p} K_{\mathrm{R}^{+}}$ & alkene & $\begin{array}{l}\log A= \\
\log k_{\text {iso }}\end{array}$ & $\mathrm{p} K_{\mathrm{R}^{+}}$ \\
\hline $2 r$ & 6.78 & -13.3 & $2 f$ & 6.41 & $-16.8^{c}$ \\
\hline $2 a$ & 7.04 & -13.5 & $2 \mathrm{~g}$ & 5.60 & $-16.1^{d}$ \\
\hline $2 b$ & 6.67 & -11.5 & $2 \mathrm{~h}$ & 5.08 & -10.4 \\
\hline $2 c$ & 6.71 & -13.7 & $\mathbf{2 i}$ & 5.95 & -12.5 \\
\hline 2d & 7.46 & -14.2 & $2 \mathbf{j}$ & 5.04 & -11.6 \\
\hline $2 e$ & 6.90 & -12.8 & $2 \mathbf{k}$ & 3.40 & -10.0 \\
\hline
\end{tabular}

${ }^{a}$ An Arrhenius activation energy $E_{\mathrm{a}}=0$ is observed (2h, 2k) or predicted for the reaction of this alkene with the diarylcarbenium ion of the specified $\mathrm{p} K_{\mathrm{R}}+$ value. ${ }^{b}$ From eq 13 using $s$ and $c$ from Table II and $\log k=\log A$ (averaged value of the reaction series). ${ }^{c}$ From $\log k$ $=-12.72-1.137 \mathrm{pK}_{\mathrm{R}^{+}}{ }^{\text {From }} \log k=-11.26-1.046 \mathrm{p} K_{\mathrm{R}^{+}}$.

right), in which the $\log k$ values $\left(-70^{\circ} \mathrm{C}\right)$ of this reaction are used as the temperature-independent substituent constants (abscissa)..$^{18}$ The slopes of these correlation lines, the reaction constants $s$, decrease with increasing temperature and become zero at the isokinetic temperature (extrapolated horizontal line). The common point of intersection is found at $\log k_{0}=6.8$, necessarily the same value as derived from the Arrhenius plot. From the point of intersection in the Hammett plot, one can derive that the carbenium ion with $\log k_{0}=6.8$ shows the same reactivity at all temperatures $\left(E_{\mathrm{a}}=0\right)$ and is therefore called the isokinetic substituent. ${ }^{18,19}$

Since carbenium ions with isokinetic substituents are characterized by $E_{\mathrm{a}}=0$, their reactivity equals the preexponential factor $(\log A)$. As $\log A$, like $\Delta S^{*}$, remains almost constant when only the substitution of the carbenium ions $\mathbf{1 - X}, \mathbf{Y}$ is altered, isokinetic substituents (characterized by $\log k_{0}$ ) can be derived from the correlations shown in Figures 2 or 4 by searching for the substituent for which $\log k$ adopts the magnitude of $\log A$. Later in this article, it will be shown that the $\log k_{0}$ values of diarylcarbenium ions are linearily correlated with their $\mathrm{p} K_{\mathrm{R}}+$ values. Therefore, we have used the well-established $\mathrm{p} K_{\mathrm{R}^{+}}$parameters ${ }^{20}$ to identify the isokinetic substituents for the different reaction series (Table III).

In most reaction series, the isokinetic substituents fall outside the range of our experimental investigations (Table III). For the reaction series with trimethylethylene $(2 \mathrm{~h})$ and tetramethylethylene (2k), the isokinetic substituent corresponds to $\mathbf{1 -} \mathbf{C H}_{3}, \mathbf{C H}_{3}\left(\mathrm{p} K_{\mathrm{R}^{+}}\right.$ $=-10.4)$ and has directly been observed: The rate of the reaction of $\mathbf{1}-\mathbf{C H}_{3}, \mathbf{C H}_{3}$ with trimethylethylene (2h), for example, was found to be independent of temperature $\left[(6.9 \pm 0.3) \times 10^{4} \mathrm{~L} \mathrm{~mol}^{-1} \mathrm{~s}^{-1}\right]$, somewhat smaller than the averaged value given in Table III. ${ }^{21}$

The selectivity reactivity relationships in Figures 3 and 5 have been generated as the differences between the reactivity-reactivity relationships in Figures 2 and 4. In analogy to this procedure, Arrhenius plots of the type shown in Figure 7 can be subtracted from each other to display selectivity as a function of reciprocal temperature (Figure 8). According to Giese, two isokinetic reaction series build up an isoselective relationship, if $\delta \Delta \Delta H^{*}=$ $T_{\text {isosel }} \delta \Delta \Delta S^{*}$. li.j If two isoentropic reaction series (i.e., $T_{\text {iso }}=\infty$ ) give rise to an isoselective relationship, the isoselective temperature must also be infinite. ${ }^{22}$ Figure 8 shows that the common point of intersection of the $\log \left(k_{2 \mathrm{e}} / k_{2 \mathrm{~b}}\right) / T^{-1}$ correlations is at ap-

(18) This kind of presentation has been suggested by Schmid and Sapunov: Schmid, R.; Sapunov, V. N. Non-formal kinetics; Verlag Chemie: Weinheim 1982; p 175 .

(19) (a) Palm, V. A.; Istomin, B. I. Reakct. Sposobn. Org. Soedin. 1969 6, 427. (b) Exner, O. Prog. Phys. Org. Chem. 1973, 10, 411 . (c) Exner, O Collect. Czech. Chem. Commun. 1974, 39, 515. (d) Schmid, R.; Soukup, R. W.: Sapunov, V. N.; Linert, W. Z. Phys. Chem., Neue Folge 1981, 126, 25. (e) Linert, W. Aust. J. Chem. 1986, 39, 199. (f) Reference 18, p 174. (20) (a) Deno, N. C.; Jaruzelski, J.; Schriesheim, A. J. Am. Chem. Soc. 1955, 77, 3044. (b) Deno, N. C.: Schriesheim. A. Ibid. 1955, 77, 3051.

(21) Preliminary communication: Schneider, R.; Mayr, H. Angew. Chem. 1986, 98, 1033: Angew. Chem., Int. Ed. Engl. 1986, 25, 1016.

(22) Exner, O.; Giese, B. Angew. Chem. 1978, 90, 816; Angew. Chem., Int. Ed. Engl. 1978, 17,775 .

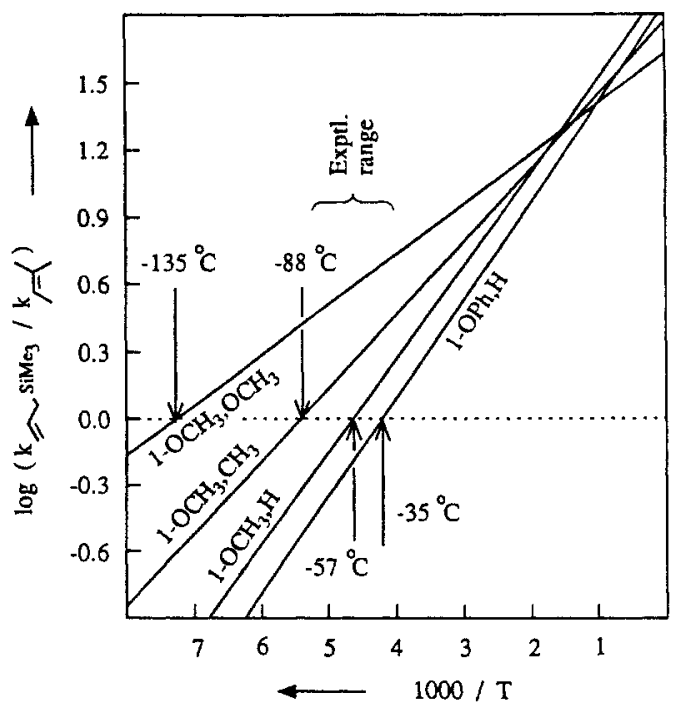

Figure 8. Selectivity of various carbenium ions $(\mathbf{1 - X}, \mathbf{Y})$ toward the nucleophiles $2 \mathrm{e} / 2 \mathrm{~h}$ as a function of reciprocal temperature.

proximately $1000 \mathrm{~K}$, close to the point expected for ideally isoentropic series.

The pair $\mathbf{2 e} / \mathbf{2} \mathrm{h}$ has been selected for another reason; however, it shows the occurrence of aselective temperatures. According to Figure 8 , at $T<-135^{\circ} \mathrm{C}$, trimethylethylene $(\mathbf{2 h})$ is more reactive than allyltrimethylsilane (2e) toward all carbenium ions investigated (enthalpy control). With increasing temperature, the selectivity decreases and becomes zero at the aselective temperature, which is different for the various carbenium ions $(-135$ for 1- $\mathrm{OCH}_{3}, \mathrm{OCH}_{3},-88$ for $\mathbf{1 -} \mathrm{OCH}_{3} \mathrm{CH}_{3},-57$ for $\mathbf{1 - O C H}, \mathrm{H}$, and -35 ${ }^{\circ} \mathrm{C}$ for $\mathbf{1 - O P h}, \mathrm{H}$ ). A further increase of temperature results in an increase of selectivity, but now with higher reactivity of allyltrimethylsilane (2e) (entropy control). Consequently, an increase of selectivity is observed as one moves away from the aselective temperature in any direction.

Negative Activation Enthalpies. The linear free energy relationships in Figure 4 show no curvature as $\Delta H^{*}$ approaches zero $\left(\Delta H^{*} \approx 0\right.$ for $1-\mathrm{CH}_{3} \mathbf{C H}_{3}+\mathbf{2 h}$, Table I). The question arises, whether this is the lower limit for $\Delta H^{*}$, or if $\Delta H^{*}$ will adopt negative values when less stabilized carbenium ions are employed (e.g., 1-H,H). Since we are unable to follow faster reactions with the apparatus described in ref 4 , a preliminary answer to this question will be derived from the results of previously described competition experiments (Figure 9).11a The activation enthalpy

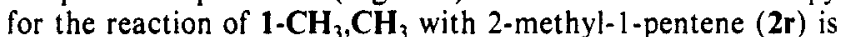
$11.6 \mathrm{~kJ} \mathrm{~mol}^{-1}, 4$ and a linear progression of the corresponding correlation line into the area of more reactive carbenium ions can be expected. In accord with this assumption, the relative rates measured toward $\mathbf{1 - H}, \mathbf{H}$ (Figure 3 ) are those expected for a linear extension of this correlation line. For the reactivity of trimethylethylene (2h), two extreme possibilities are feasible:

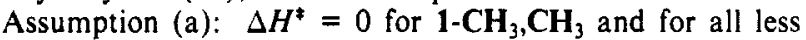
stabilized carbenium ions. Since $\Delta S^{*}$ is independent of $\mathrm{X}$ and $\mathrm{Y}$, the reactivity increase toward $\mathbf{2 h}$, which is observed as the electron-releasing ability of the para substituents is reduced (moving from left to right in Figure 9), should terminate as 1- $\mathrm{CH}_{3}, \mathrm{CH}_{3}$ is passed. All less stabilized carbenium ions should possess the same reactivity toward $\mathbf{2 h}$ as $\mathbf{1 -} \mathbf{C H}_{3}, \mathbf{C H}_{3}$ (Figure 9, horizontal dashed line). In this case, $\mathbf{1 - H}, \mathbf{H}$ should react faster with $2 \mathbf{r}$ than with $\mathbf{2 h}$.

Assumption (b): $\Delta H^{*}$ adopts negative values, and the rate equilibrium correlation in Figure 9 is not affected when $\Delta H^{*}$ changes sign. As the two straight lines for $2 \mathrm{~h}$ and $2 \mathrm{r}$ diverge to the right of Figure 9, one would now expect that the selectivity $\left(\log k_{2 h} / k_{2 r}\right)$ increases as the stabilization of $\mathbf{1 - X , Y}$ is further decreased.

The latter situation is experimentally found: While $\mathbf{1}-\mathbf{C H}_{3}, \mathbf{C H}_{3}$ favors $2 \mathrm{~h}$ over $\mathbf{2 r}$ by a factor of 20 (direct rates, this work) or 24 


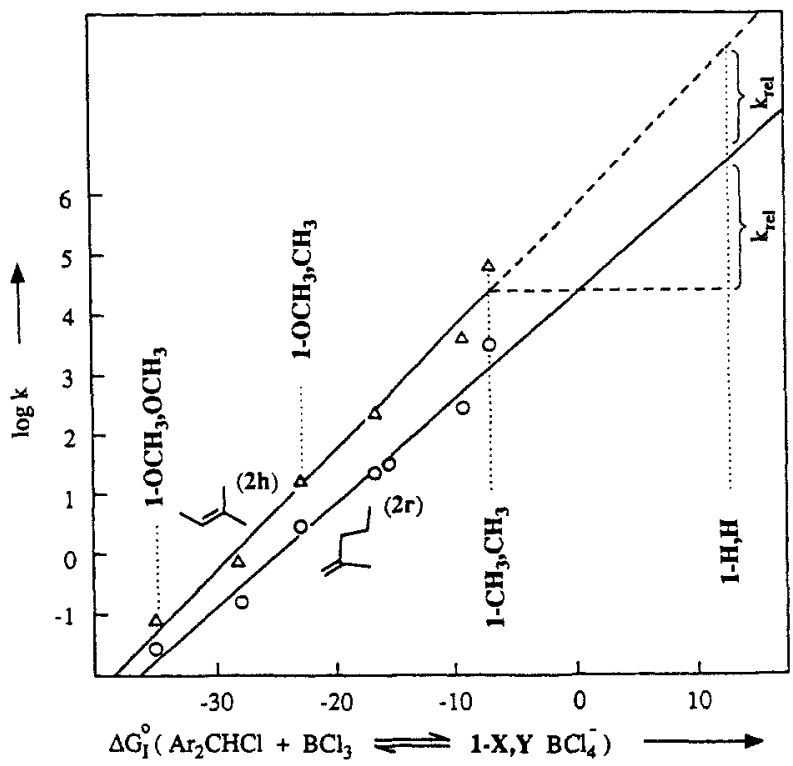

Figure 9. Are negative activation enthalpies realized? Correlations of the reactivities of $\mathbf{1 - X}, \mathbf{Y}$ toward $2 \mathrm{~h}$ and $2 \mathrm{r}$ with the ionization free energies of the corresponding diarylmethyl chlorides.

(competition experiments ${ }^{1 / a}$ ), a $k_{2 \mathrm{~h}} / k_{2 \mathrm{r}}$ ratio of 44 has been reported for the unsubstituted benzhydryl cation 1-H,H. ${ }^{11 a}$ Since the linear extrapolations in Figure 9 predict a ratio of 76 (a deviation of only 0.24 on the logarithmic scale), we conclude that the linear free energy relationships encountered in this study do not experience a break as the sign of $\Delta H^{*}$ is changing. In agreement with this analysis, negative activation enthalpies have also been reported for the propagation reaction in carbocationic polymerizations of $\alpha$-methylstyrene, ${ }^{23 a} p$-methoxystyrene, ${ }^{23 b}$ and cyclopentadiene. ${ }^{23 c}$

The physical significance of negative activation enthalpies is still under debate. ${ }^{24}$ The classical explanation, rapid reversible formation of an intermediate, which decomposes to the reactants faster than to the products, is shown in Figure 10a. If the negative value of $\Delta H^{0}$ of the preequilibrium is greater than the enthalpic barrier of the product-forming reaction, a negative temperature coefficient will be observed. It has been suggested, however, that negative activation enthalpies are also possible for one-step reactions if a large $T \Delta S$ term shifts the maximum of the $\Delta G$ curve into a range on the reaction coordinate where $\Delta H$ is already negative (Figure 10c) ${ }^{24 d-1}$ Since both models agree that the $T \Delta S$ term is responsible for the $\Delta G$ maximum being later on the reaction coordinate than the $\Delta H$ maximum, the two models can be transformed into each other by changing the magnitude of the dip in the energy profile (Figure 10b). As a small dip may correspond to a weak interaction in the encounter complex, there is no rigid borderline between the two cases for reactions occurring in solution. While the reversible formation of the intermediates (3-X,Y)k has been proven, ${ }^{16}$ the negative activation enthalpies deduced for reactions of $\mathbf{1 -} \mathbf{C H}_{3}, \mathbf{C H}_{3}$ and more reactive carbenium ions with $\mathbf{2 h}$ are probably better described by curves $\mathrm{b}$ or $\mathrm{c}$ in Figure 10.

Prediction of Further Carbenium Ion Reactivities. Though the rate equilibrium relationships (eq 7) are not of such high quality

(23) (a) Villesange, M.; Sauvet, G.; Vairon, J. P.; Sigwalt, P. J. Macromol. Sci., Chem. 1977, All, 391. (b) Cotrel, R.; Sauvet, G.; Vairon, J. P.; Sigwalt, P. Macromolecules 1976, 9, 931. (c) Sauvet, G.; Vairon, J. P.; Sigwalt, P. Eur. Polym. J. 1974, 10, 501

(24) (a) Leenson, I. A.; Sergeev, G. B. Russ. Chem. Rev. (Engl. Transl) 1984, 53, 417. (b) Davis, D. D.; Huie, R. E.; Herron, J. T. J. Chem. Phys. 1973, 59, 628. (c) Zahniser, M. S. Kaufman, F. J. Chem. Phys. 1977, 66, 3673. (d) Benson, S. W. Thermochemical Kinetics, 2nd ed.; Wiley: New York, 1976; p 15. (e) Houk, K. N.; Rondan, N. G.; Mareda, J. Tetrahedron 1985, 4l, 1555. (f) Houk, K. N.; Rondan, N. G. J. Am. Chem. Soc. 1984, 106, 4293. (g) Doubleday, C., Jr.; Camp, R. N.; King, H. F.; Mclver, J. W. Muilally, D.; Page, M. J. Am. Chem. Soc. 1984, 106, 447. (h) Koenig, T.; Finke, R. G. J. Am. Chem. Soc. 1988, 110, 2657.

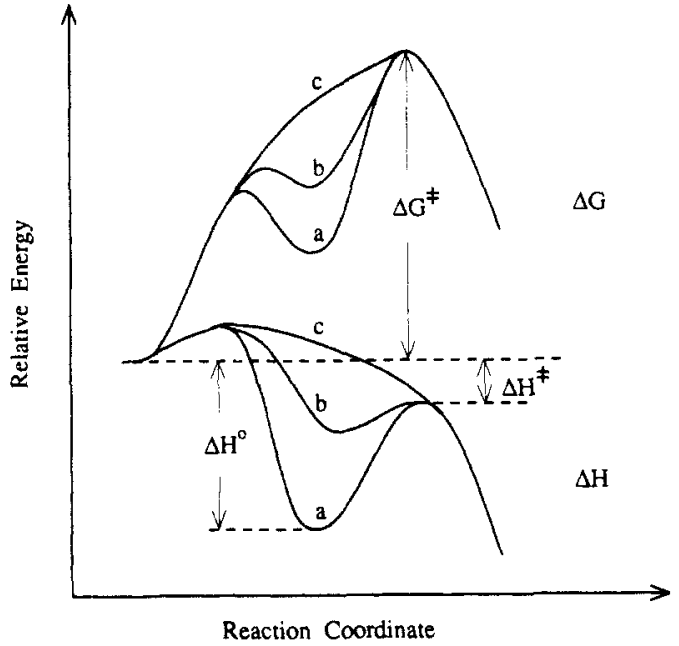

Figure 10. Two-step and one-step reactions with negative activation enthalpies.

as the reactivity-reactivity relationships described by eq 5 , eq 7 is a highly valuable correlation as it allows for the estimation of reactivities of diarylcarbenium ions that have not been calibrated by kinetic experiments. Equation 9 represents an alternative version of eq 7 and yields the rate constants $\log k_{0}$ for the reactions of diarylcarbenium ions with 2-methyl-1-pentene $(2 \mathrm{r})$ at $-70^{\circ} \mathrm{C}$ from the corresponding ionization free energies $\Delta G_{1}^{\circ}\left(\mathrm{Ar}_{2} \mathrm{CHCl}\right.$ $+\mathrm{BCl}_{3} \rightleftharpoons \mathrm{ArCH}{ }^{+} \cdot \mathrm{BCl}_{4}^{-}$), which are listed in ref $13 \mathrm{~b}$. As the ionization free energies are linearily correlated with the $\mathrm{p} K_{\mathrm{R}^{+}}$ value ${ }^{20}$ and the corresponding ethanolysis rate constants, ${ }^{13 \mathrm{~b}}$ these data can also be used for calculating $\log k_{0}$ of the reference reaction 4 (eqs 10,11 ). When $\log k_{0}$ in eq 5 is substituted by

$$
\begin{aligned}
\log k_{0} & =4.33+0.173 \Delta G_{1}^{\circ}(r=0.990 ; 7 \text { points }) \\
\log k_{0} & =-7.42-1.07 \mathrm{p} K_{\mathrm{R}^{+}}{ }^{25}(r=0.991 ; 4 \text { points })
\end{aligned}
$$

$\log k_{0}=0.90-1.26 \log k_{\text {solv }}{ }^{26}(r=0.973 ; 7$ points $)$

the expressions 9-11, the eqs $12-14$ are obtained, which allow the calculation of rate constants $\left(\mathrm{CH}_{2} \mathrm{Cl}_{2},-70^{\circ} \mathrm{C}\right)$ for the reactions of all nucleophiles listed in Table II $(s, c)$ with diarylcarbenium ions, for which $\Delta G_{1}^{\circ}, \mathrm{p} K_{\mathrm{R}^{+}}$, or solvolysis rates are available.

$$
\begin{gathered}
\log k=4.33 s+0.173 s \Delta G_{1}^{\circ}+c \\
\log k=-7.42 s-1.07 s p K_{R^{+}}+c \\
\log k=0.90 s-1.26 s \log k_{\text {solv }}+c
\end{gathered}
$$

For eqs $12-14, s$ and $c$ from Table II; $\Delta G_{l}^{\circ}$ and ethanolysis rate constants $\left(k_{\text {solv }}, 25^{\circ} \mathrm{C}\right)$, from ref $13 \mathrm{~b} ; \mathrm{p} K_{\mathrm{R}^{+}}$from ref 20 .

Figure 2 showed that alkenes with identical substitution at the electrophilically attacked vinylic position give parallel reactivity-reactivity correlations (constant selectivity). Therefore, eqs 12-14 can also be used to estimate reaction rates of vinyl compounds, for which the reactivity toward any of the carbenium ions 1-X,Y is known (e.g., $\mathbf{1 - O C H}, \mathbf{H}){ }^{5}$ In this case, the rate constant of a sterically related compound should be calculated from eqs 12-14 and multiplied with the relative reactivity of the two alkenes toward any carbenium ion 1-X,Y (see following examples).

Correlation 12 will now be used to estimate rate constants for the reaction of the unsubstituted benzhydryl cation $(\mathbf{1}-\mathbf{H}, \mathbf{H})$ with the hydrocarbons listed in Table IV. With $\Delta G_{I}^{\circ}=12.9 \mathrm{~kJ} \mathrm{~mol}^{-1}$

(25) $\mathrm{p} K_{\mathrm{R}^{+}}=-10.4\left(1-\mathrm{CH}_{3}, \mathrm{CH}_{3}\right),-5.71\left(1-\mathbf{O C H}{ }_{3}, \mathbf{O C H}\right)$, ref $20 \mathrm{a} . \mathrm{p} K_{\mathrm{R}^{+}}$ $=-7.9\left(\mathbf{1}-\mathbf{O C H}_{3}, \mathrm{H}\right)$, ref 20b. $\mathrm{p} K_{\mathrm{R}^{+}}=-7.36\left(\mathbf{1}-\mathbf{O C H}_{3}, \mathbf{C H}_{3}\right)$, Mindl, J.; Vecera M. Collect. Czech. Chem. Commun. 1971, 36, 3621 .

(26) Ethanolysis rate constants at $25^{\circ} \mathrm{C}$, ref $13 \mathrm{~b}$ 
Table IV. Comparison of Calculated Addition Rate Constants (Column 4) for the Diphenylcarbenium Ion $(1-\mathrm{H}, \mathrm{H})$ with Experimental Values (Column 5)

\begin{tabular}{|c|c|c|c|c|}
\hline compound & $\begin{array}{c}\log k \\
\left(\mathrm{CH}_{2} \mathrm{Cl}{ }_{2}\right. \\
\left.-70^{\circ} \mathrm{C}\right)\end{array}$ & $\underset{\mathrm{J} \mathrm{mol}^{-1}}{\Delta \mathrm{K}^{*} \mathrm{~K}^{-1}}$ & 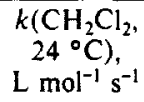 & $\begin{array}{c}k\left(\left(\mathrm{CH}_{2} \mathrm{Cl}\right)_{2},\right. \\
\left.244^{\circ} \mathrm{C}\right),{ }^{b} \\
\mathrm{Lol}^{-1} \mathrm{~s}^{-1}\end{array}$ \\
\hline & 6.58 & -116 & $5 \times 10^{6}$ & $9.5 \times 10^{6}$ \\
\hline & 2.18 & -139 & $2 \times 10^{3}$ & $<10^{5}$ \\
\hline & 6.24 & -108 & $4 \times 10^{6}$ & $7.1 \times 10^{6}$ \\
\hline & 6.50 & -108 & $7 \times 10^{6}$ & $2.7 \times 10^{7}$ \\
\hline & 3.33 & -108 & $4 \times 10^{4}$ & $<10^{5}$ \\
\hline
\end{tabular}

averaged value, of the reaction series for $\mathbf{2 a}$ and $\mathbf{2 d}$ (Table I) other values estimated from data in refs. ${ }^{6}$ Reference 27.

for $\mathbf{1 - H}, \mathbf{H}^{13 \mathrm{~b}}$ and the $s$ and $c$ values of Table II, one can calculate the rate constants $\log k\left(\mathrm{CH}_{2} \mathrm{Cl}_{2},-70^{\circ} \mathrm{C}\right)$ of $2 \mathrm{a}$ and $2 \mathrm{~d}$. From the reactivity ratios ${ }^{5}$ (propene/ $2 \mathrm{a}=4.03 \times 10^{-5}, 2,3$-dimethyl1,3-butadiene $/ \mathbf{2 d}=1.81$, and 1,3 -butadiene $/ 2 \mathrm{~d}=1.24 \times 10^{-3}$ )

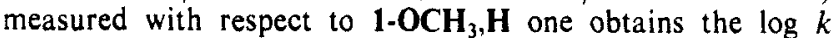
$\left(\mathrm{CH}_{2} \mathrm{Cl}_{2},-70^{\circ} \mathrm{C}\right)$ values for the other compounds of Table IV. These numbers can now be converted into the rate constants at $24{ }^{\circ} \mathrm{C}$, since $\Delta S^{*}$ can again be assumed to remain constant throughout a reaction series. Finally, considering that the reaction of 1-OCH $\mathrm{CH}_{3}, \mathrm{OCH}_{3}$ with 2-methyl-1-pentene was found to be 1.5 times faster in 1,2-dichloroethane than in dichloromethane, the agreement between the estimated rate constants in column 4 (Table IV) and those measured for radiolytically generated diphenylcarbenium ions by Dorfman ${ }^{27}$ (Table IV, column 5 ) is better than expected. In view of the high sensitivity of the addition rate constants on the stabilization of the carbenium ions (eq 7), we expect the benzyl cation $\left(\mathrm{Ph}-\mathrm{CH}_{2}{ }^{+}\right)$to be considerably more reactive than the benzhydryl cation. Therefore, we believe that the pulse radiolytically generated species, which reacts twice as fast with isobutene and 1,3-cyclohexadiene as $\mathrm{Ph}_{2} \mathrm{CH}^{+}$, cannot be the previously suggested parent benzyl cation. ${ }^{27}$

\section{Conclusions}

Ritchie type correlations, i.e. constant selectivity relationships are observed for reactions of diarylcarbenium ions with alkenes, if the substituents close to the reaction centers are kept constant. Under these conditions, the transition-state structure remains unaffected even if the reactivity is strongly altered by remote substituents. Substituent variations at the reaction center give rise to a variation of the transition-state structure, and linear free energy relationships with different slopes are observed.

Based on the rate constants and correlation equations presented in this and the preceding two articles, it has become possible to estimate rate constants for almost any diarylcarbenium ion with a large variety of alkenes. Since the correlations reported in this work have been found to hold also for the reactions of $1-X, Y$ with allylsilanes, allylgermanes, allylstannes, and aromatic compounds, there is hope that a large body of carbenium ion nucleophile combinations can be described by a small set of kinetic parameters. Deviations from eqs 12-14, which may be encountered when the benzhydryl cations are replaced by other types of carbenium ions, require further examination.

Acknowledgment. We thank Dr. C. Schade for determining the rate constants of $\mathbf{2 f , g}$ and the Deutsche Forschungsgemeinschaft for financial support.

Note Added in Proof. The discussion on negative activation enthalpies (Figures 9 and 10 ) was based on the constancy of $\Delta S^{\ddagger}$ during variation of the para-substituents in $\mathbf{1 - X , Y . ~ A ~ r e c e n t ~}$ paper ${ }^{28}$ suggests that this constancy may not hold for reactions with $\Delta H^{*}<0$. Therefore, the high reactivity ratio $\left(k_{2 \mathrm{~b}} / k_{2 \mathrm{r}}=\right.$ 44 toward $\mathbf{1}-\mathbf{H}, \mathbf{H})$ might also reflect a change of the activation entropy, i.e., $\Delta S^{*}$ for the reaction $\mathbf{1}-\mathbf{H}, \mathbf{H}+\mathbf{2 h}$ may be less negative than for the other reactions of this series.

Supplementary Material Available: Tables of reaction conditions (concentrations) and rate constants of the individual kinetic runs and Eyring and Arrhenius parameters (14 pages). Ordering information is given on any current masthead page.

(27) Wang, Y.; Dorfman, L. M. Macromolecules 1980, 13,63

(28) Scaiano, J. C.; Wintgens, V.; Haider, K.; Berson, J. A. J. Am. Chem. Soc. $1989,111,8732$

\title{
Tunneling in Elimination Reactions. Tests of Criteria for Tunneling Predicted by Model Calculations ${ }^{1,2}$
}

\author{
Mohammed Amin, Robin C. Price, and William H. Saunders, Jr.* \\ Contribution from the Department of Chemistry, University of Rochester, \\ Rochester, New York 14627. Received September 18, 1989
}

\begin{abstract}
Isotope effects in E2 reactions of mixtures of $\mathrm{ArCL}_{2} \mathrm{CH}_{2} \mathrm{X}$ and $\mathrm{ArCLTCH}_{2} \mathrm{X}(\mathrm{L}=\mathrm{H}$ or D) were determined by isotope fractionation methods. The temperature dependences of the secondary isotope effects, $k_{\mathrm{H}}^{\mathrm{H}} / k_{\mathrm{H}}^{\mathrm{T}}$ (the subscript represents the transferred and the superscript represents the nontransferred atom) were abnormal as predicted by model calculations with tunneling when $\mathrm{Ar}=\mathrm{Ph}$ and $\mathrm{X}=\mathrm{NMe}_{3}$ in $\mathrm{EtO}^{-} / \mathrm{EtOH}\left(A_{\mathrm{aH}} / A_{\mathrm{aT}}=0.705 \pm 0.024\right)$ and when $\mathrm{Ar}=p-\mathrm{ClPh}$ and $\mathrm{X}$ $=$ OTs in $t-\mathrm{BuO}^{-} / t-\mathrm{BuOH}\left(A_{\mathrm{aH}} / A_{\mathrm{aT}}=0.704 \pm 0.023\right)$. When $\mathrm{Ar}=\mathrm{Ph}$ and $\mathrm{X}=\mathrm{Br}$ in $t-\mathrm{BuO}^{-} / t-\mathrm{BuOH}$, the temperature dependence is not definitely abnormal $\left(A_{\mathrm{aH}} / A_{\mathrm{aT}}=0.927 \pm 0.040\right)$, but the result can be shown still to be consistent with tunneling. The secondary effects $k_{\mathrm{D}}^{\mathrm{D}} / k_{\mathrm{D}}^{\mathrm{T}}$ at $50^{\circ} \mathrm{C}$ for $\mathrm{Ar}=\mathrm{Ph}, \mathrm{X}=\mathrm{NMe}_{3}$ in $\mathrm{EtO}-/ \mathrm{EtOH}$ and $\mathrm{Ar}=p-\mathrm{ClPh}, \mathrm{X}=\mathrm{OTs}$ in $t$-BuO $/ t$ - BuOH were $1.0314 \pm 0.0099$ and $1.0274 \pm 0.0077$, respectively, and remain well below the $k_{\mathrm{H}}^{\mathrm{H}} / k_{\mathrm{H}}^{\mathrm{H}}$ values $(1.2042 \pm 0.0149$ and 1.1907 \pm 0.0122 , respectively), when converted to $k_{\mathrm{H}}^{\mathrm{H}} / k_{\mathrm{H}}^{\mathrm{T}}$ values by $k_{\mathrm{H}}^{\mathrm{H}} / k_{\mathrm{H}}^{\mathrm{T}}=\left(k_{\mathrm{D}}^{\mathrm{D}} / k_{\mathrm{D}}^{\mathrm{T}}\right)^{3.26}$, observations again diagnostic of tunneling. Efforts to apply the same criterion to primary isotope effects, $k_{\mathrm{D}}^{D} / k_{\mathrm{T}}^{\mathrm{D}}$ and $k_{\mathrm{H}}^{H} / k_{\mathrm{T}}^{\mathrm{H}}$, were inconclusive.
\end{abstract}

The possibility of hydrogen tunneling in chemical reactions was recognized almost from the beginning of quantum theory.
General acceptance of the idea has been much slower in coming because of the difficulty in obtaining unequivocal experimental 